\title{
Increased Expression of Hypoxia-Inducible Factor $1 \alpha$ in Coeliac Disease
}

\author{
ÁDÁM VANNAY, ERNA SZIKSZ, ÁGNES PRÓKAI, GÁBOR VERES, KRISZTA MOLNÁR, DOROTTYA NAGY SZAKÁL, \\ ANNA ÓNÓDY, ILMA R. KORPONAY-SZABÓ, ANDRÁS SZABÓ, TIVADAR TULASSAY, ANDRÁS ARATÓ, \\ AND BEÁTA SZEBENI
}

\begin{abstract}
First Department of Pediatrics [A.V., E.S., A.P., G.V., K.M., D.N.S., A.O., A.S., T.T., A.A., B.S.], Semmelweis University, H-1083 Budapest, Hungary; Department of Gastroenterology-Nephrology [I.R.K.-S.], Heim Pal Children's Hospital, H-1084 Budapest, Hungary; Research Group for Pediatrics and Nephrology [A.V., E.S., T.T., B.S.], Semmelweis University and Hungarian Academy of Sciences,
\end{abstract} H-1083 Budapest, Hungary

\begin{abstract}
Previously, it has been suggested that hypoxiainducible factor (HIF) 1 signaling may play determinative role in the maintenance of the barrier function of the intestinal epithelium in inflammatory bowel disease. Our aim was to depict the alteration of HIF- $1 \alpha$ and related genes in celiac disease (CD) where the importance of the barrier function is well known. Duodenal biopsy specimens were collected from 16 children with untreated CD, 9 children with treated CD and 10 controls. HIF- $1 \alpha$, trefoil factor 1 (TFF1), ecto-5-prime nucleotidase (CD73), and multi drug resistance gene 1 (MDR1) mRNA and HIF-1 $\alpha$ protein expression were determined by real-time PCR and Western blot, respectively. Localization of HIF- $1 \alpha$ was determined by immunofluorescent staining. We found increased HIF- $1 \alpha$ and TFF1 mRNA and HIF- $1 \alpha$ protein expression in the duodenal mucosa of children with untreated CD compared with controls or children with treated CD $(p<0.05)$. In untreated CD children, HIF- $1 \alpha$ staining was present in cytoplasmic and nuclear region of the villous enterocytes. In treated CD mRNA expression of CD73 and MDR1 were increased compared with controls $(p<0.01$ and 0.05 , respectively). Our results of increased mucosal HIF- $1 \alpha$ expression in $\mathrm{CD}$ children suggest the contribution of this signaling pathway in the pathomechanism of CD. (Pediatr Res 68: 118-122, 2010)
\end{abstract}

$\mathrm{C}$ eliac disease $(\mathrm{CD})$ is due to immune-mediated gluten intolerance, which affects around $1 \%$ of the society (1-4). Small intestinal epithelial cells are anatomically positioned to provide a barrier function to luminal antigens. Our current understanding of $\mathrm{CD}$ is that this barrier function is damaged, which leads to the leakage of cereal proteins across the intestinal epithelium and initiates inflammation in the lamina propria $(5,6)$.

Recently, it has been proposed that hypoxia-inducible factor-1 $\alpha$ (HIF) may elicit a barrier protective function in hypoxiainduced inflammation of the intestine $(7,8)$. HIF- $1 \alpha$ is a regulator of cellular response to hypoxia (9). HIF-1 is a heterodimeric transcription factor, which contains an $\alpha$ - and a $\beta$-subunits. Under normoxic conditions, HIF- $1 \alpha$ is hydroxy-

Received January 14, 2010; accepted April 21, 2010.

Correspondence: Beáta Szebeni, Ph.D., Research Group for Pediatrics and Nephrology, Semmelweis University and Hungarian Academy of Sciences, Bókay J. u. 53-54, H-1083 Budapest, Hungary; e-mail: szebeni@gyer1.sote.hu

Supported by funds from the Hungarian National Scientific Research Foundation Grant (OTKA 71730, T046082, OTKA-K81117), and Grant of the Ministry of Health (ETT 435/2006, ETT- 028-02) and TÁMOP-4.2.2-08/1/KMR-2008-0004.

A.V. and E.S. contributed equally to this work. lated by proline-hydroxylases (PHDs) leading to ubiquitylation by von-Hippel-Lindau and to subsequent degradation (10). However, under hypoxic conditions-when the PHDs are inhibited-HIF- $1 \alpha$ stabilizes and translocates to the nucleus. The active HIF-1 heterodimer then may initiate the transcription of different genes (11). Some of these genes such as trefoil factor 1 (TFF1), ecto-5-prime nucleotidase (CD73), and multi drug resistance gene 1 (MDR1) may exert barrier protective function (12-14).

In intestinal epithelial cell targeted expression of either mutant HIF- $1 \alpha$ (reduced expression of HIF- $1 \alpha$ ) or von Hippel-Lindau gene (overexpression of HIF-1 $\alpha$ ) correlated with the symptoms of colitis (15). Although lack of HIF- $1 \alpha$ resulted in increased intestinal epithelial permeability, mortality, and loss of weight, overexpression of HIF- $1 \alpha$ was protective in a mouse model of colitis.

Although induction of gene transcription by HIF-1 heterodimer is normally associated with hypoxia, it is now established that HIF-1 signaling can be triggered under inflammatory conditions (16). To investigate the possible role of HIF- $1 \alpha$ in the pathomechanism of CD, here we examined its amount and localization and the expression of some HIF-1 regulated genes in treated and untreated $\mathrm{CD}$ as well as in control patients.

\section{METHODS}

Patients. Duodenal biopsy samples from 16 children with untreated [boys: six, girls: 10; median age: 6.7 y (3.7-13.9)] and nine with treated [boys: four, girls: five; median age: 6.7 y $(4.9-12.7)]$ CD were collected. Biopsy samples of seven children with untreated $\mathrm{CD}$ were taken at the time of diagnosis, before the introduction of a gluten-free diet. The nine other children from whom duodenal biopsies were obtained before (untreated CD) - and $1.5 \mathrm{y}$ (range: 1.1-2.5) after exclusion of gluten from the diet (treated CD). The diagnosis of CD was based on European Society for Paediatic Gastroenterology, Hepatology and Nutrition (ESPGHAN) criteria (17). All untreated CD children had anti-endomysium IgA positivity and subtotal villous atrophy of the intestinal mucosa. In case of treated CD children full clinical remission was observed on the diet and no serum anti-endomysium antibodies were detected.

The control group consisted of 10 children [boys: four, girls: six; age: $8 \mathrm{y}$ (1.7-13)] who were investigated for either growth retardation or chronic diarrhea and an upper gastrointestinal endoscopy was part of their diagnostic

\footnotetext{
Abbreviations: CD, coeliac disease; CD73, ecto-5-prime nucleotidase; HIF, hypoxia inducible factor; IBD, inflammatory bowel disease; MDR1, multi drug resistance gene 1; TFF1, trefoil factor 1
} 
Table 1. Nucleotide sequence of specific primer pairs and probes applied for the real time detection of $H I F-1 \alpha, T F F 1$, and GAPDH

\begin{tabular}{clc}
\hline Gene & \multicolumn{1}{c}{ Primer pairs and probes } & $\begin{array}{c}\text { Product } \\
\text { length }\end{array}$ \\
\hline HIF1- $\alpha$ & $\begin{array}{l}\text { forward: 5'- CCA GTA CTC GGC GAA GTA AA-3' } \\
\text { reverse: 5' }\end{array}$ & 176 bp ACC ATC CAA GGC TTT CAA ATA A-3' \\
TFF1 & $\begin{array}{l}\text { forward: 5'-TGG CCA CCA TGG AGA ACA AG-3' } \\
\text { reverse: 5'-TGG AGG GAC GTC GAT GGT ATT A-3' }\end{array}$ & 233 bp \\
GAPDH & $\begin{array}{l}\text { forward: 5'-CAC CAC CAT GGA GAA GGC TG-3' } \\
\text { reverse: 5'-GTG ATG GCA TGG ACT GTG-3' }\end{array}$ & 240 bp \\
\hline
\end{tabular}

procedure. The intestinal mucosa was normal in all of them and no significant age- or sex-related differences were observed among children with untreated $\mathrm{CD}$, treated $\mathrm{CD}$, and controls $(p=\mathrm{NS})$.

Biopsy samples were immediately frozen and stored at $-80^{\circ} \mathrm{C}$ until further analysis. Written informed consent was obtained from parents of each participant before the procedure, and the study was approved by Semmelweis University Regional and Institutional Committee of Science and Research Ethics (TUKEB: 73/2003).

RNA isolation and real time RT-PCR. HIF- $1 \alpha$, TFF1, and glyceraldehyde-3-phosphate dehydrogenase (GAPDH) mRNA expression were determined by SYBR Green real-time RT-PCR on LightCycler480 system (Roche Diagnostics, Mannheim, Germany). The sequences of the specific primer pairs for HIF- $1 \alpha$, TFF1, and GAPDH are presented in Table 1 . To detect CD73 and MDR1 specific RealTime ready Catalog Assays were used (Catalog No.: 05532957001, Roche Diagnostics).

PCRs were performed in a final volume of $20 \mu \mathrm{L}$. The reaction mix contained $10 \mu \mathrm{L}$ of the Brillant II Fast SYBR Green QPCR Master Mix (Stratagene, La Jolla, CA), $500 \mathrm{nmol} / \mathrm{L}$ of each PCR primers (Invitrogen, Carlsbad, CA), and $5 \mu \mathrm{L}$ of cDNA. The conditions of PCRs for HIF- $1 \alpha$, TFF1, CD73, MDR1 were as follows: one cycle for $2 \mathrm{~min}$ at $95^{\circ} \mathrm{C}, 5$ and then $20 \mathrm{~s}$ at $95^{\circ} \mathrm{C}$ (denaturing), $40 \mathrm{~s}$ at $60^{\circ} \mathrm{C}$ (annealing and extension) for several cycles. Conditions for GAPDH: one cycle for $8 \mathrm{~min}$ at $95^{\circ} \mathrm{C}, 50$ cycles for $4 \mathrm{~s}$ at $95^{\circ} \mathrm{C}$, for $8 \mathrm{~s} 55^{\circ} \mathrm{C}$ and for $22 \mathrm{~s} 72^{\circ} \mathrm{C}$ with a single fluorescence detection point at the end of the annealing segment.

Results were analyzed by LightCycler480 software (Roche Diagnostics). Quantification was performed with second derivative method by monitoring the cycle number at which the fluorescent sign could be distinguished from the background (crossing point). The mRNA expression of HIF-1 $\alpha$ was determined by comparison with GAPDH as internal control from the same sample.

Protein isolation and quantification of HIF-1 $\alpha$ levels. Duodenal biopsy samples of each group were homogenized in a buffer containing $10 \mu \mathrm{g} / \mathrm{mL}$ leupeptin, $10 \mu \mathrm{g} / \mathrm{mL}$ aprotinin, $1 \%$ Triton $\mathrm{X}-100,0.1 \mathrm{M}$ Tris- $\mathrm{HCl}(\mathrm{pH}=8.0)$, $1 \mathrm{mM}$ ethylene glycol-bis(2-aminoethylether), $N, N, N^{\prime}, N^{\prime}$-tetracic acid (EGTA), $5 \mathrm{mM} \mathrm{NaF}, 1 \mathrm{mM}$ phenylmethane-sulfonyl fluoride, and $10 \mathrm{mM}$ Na-orthovanadate $\left(\mathrm{Na}_{3} \mathrm{VO}_{4}\right)$ (each substance was purchased from Sigma Chemical Co.-Aldrich Co., St. Louis, MO). The lysed samples were centrifuged $\left(10,000 \mathrm{~g}, 10 \mathrm{~min}, 4^{\circ} \mathrm{C}\right)$ to pellet nuclei and large cellular fragments. Protein concentration of the supernatants was determined by Bradford assay (Bio-Rad Laboratories, Hercules, CA). Twenty micrograms of protein samples were separated by $12 \%$ SDS-PAGE (SDS-PAGE) at $120 \mathrm{~V}(\sim 40 \mathrm{~mA})$ for 90 min (Penguin Dual-Gel Water Cooled Systems, Owl, NH). Pre-stained protein mixture (BenchMark, GIBCO/BRL, Eggenstein, Germany) was used as marker of molecular mass. Then the separated proteins were transferred to nitrocellulose membrane (Hybond ECL, AP Biotech, Buckinghamshire, UK) in transfer buffer containing Tris, glycine, and methanol at $70 \mathrm{~V},(\sim 220 \mathrm{~mA})$ for $90 \mathrm{~min}$ (MiniTank electroblotter, Owl, NH). Nonspecific binding sites were blocked for $1 \mathrm{~h}\left(23^{\circ} \mathrm{C}\right)$ in a blot solution containing 5\% nonfat milk powder and PBS. Then blots were incubated for $60 \mathrm{~min}\left(23^{\circ} \mathrm{C}\right)$ with rabbit polyclonal antibody raised against the human HIF-1 $\alpha$ (Santa Cruz Biotechnology Inc., Santa Cruz, CA) diluted to 1:500. Blots were then washed and incubated with peroxidase-conjugated goat anti-rabbit $\operatorname{IgG}$ secondary antibody (Santa Cruz Biotechnology Inc.) diluted to 1:1000 for $30 \mathrm{~min}$. Equal protein loading to the gel was confirmed by staining with a goat polyclonal antibody raised against the carboxy terminus of the $\beta$ actin [Actin (C-11) goat polyclonal IgG, Santa Cruz Biotechnology Inc] diluted to 1:200. Immunoreactive bands were visualized using the enhanced chemiluminescence Western blotting detection protocol (AP Biotech, Buckinghamshire, UK). The negatives were analyzed by computerized densitometry (Gel-Pro Analyser 3.1 software, Media Cybernetics, Bethesda, MD).

Immunofluorescent staining. Duodenal biopsy samples were snap-frozen and embedded in Shandon cryomatrix (ThermoElectron Co, Waltham, MA) and then cut to $5 \mu \mathrm{m}$ slides. Slides were first incubated for $60 \mathrm{~min}$ at RT with anti HIF- $1 \alpha$ rabbit polyclonal IgGantibody (Santa Cruz Biotechnology) diluted to 1:100. After repeated washing, slides were incubated with Alexa Fluor $488 \mathrm{~F}\left(\mathrm{ab}^{\prime}\right)_{2}$ fragment of goat anti-rabbit IgG (Invitrogen, Carlsbad, CA) and Alexa Fluor $568 \mathrm{~F}(\mathrm{ab})_{2}$ fragment of goat anti-rabbit IgG (A-11036, Invitrogen, Carlsbad, CA) diluted to $1: 100$ for $30 \mathrm{~min}$ at RT. DNA was stained with Hoechst 33342 (Sigma Chemical Co.-Aldrich Company Ltd, Gillingham, UK) for $10 \mathrm{~min}$ at RT diluted to 1:1000. Finally slides were rinsed in PBS and cover slipped with Vectashield fluorescent mounting medium (Vector Laboratories, Burlingame, CA). Appropriate controls were performed omitting the primary antibodies to assure their specificity and to avoid autofluorescence.

To visualize the stained tissues on the sections, Zeiss LSM 510 Meta confocal laser scanning microscope (Carl Zeiss, Jena, Germany) was used equipped with an inverted Axiovert $200 \mathrm{M}$ microscope, $20 \times$ Plan Apochromat (NA $=0,80)$ and $63 \times$ Plan Apochromat oil immersion DIC objectives $(\mathrm{NA}=1,4)$.

Statistical analysis. Data were analyzed using Statistica 7.0 software (StatSoft Inc., Tulsa, OK). After testing the normality with Shapiro-Wilk's test, Mann-Whitney test was used to determine the differences among all groups for HIF- $1 \alpha$ mRNA and protein expression levels in duodenal mucosa. Data were considered to be significantly different if $p$ was less than 0.05 . Values for all measurements were expressed as mean \pm SEM.

\section{RESULTS}

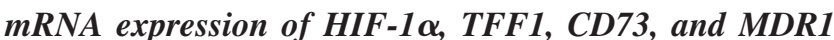
mRNA in the duodenal mucosa. Figure 1 shows the mRNA expression of HIF- $1 \alpha$, and Figure 2, the mRNA expression of TFF1, CD73, and MDR1 as detected in the duodenal mucosa of samples from children with untreated $\mathrm{CD}$, children with treated $\mathrm{CD}$ and controls. HIF- $1 \alpha$ mRNA expression was increased in the duodenal mucosa of children with untreated $\mathrm{CD}$ as well as children with treated CD compared with controls ( $p<0.01$ and $p<0.01$, respectively). In the duodenal mucosa of children with treated CD, HIF- $1 \alpha$ mRNA level was decreased in comparison to children with untreated $C D$ $(p<0.05)$. The mRNA expression of TFF1 was significantly higher in the duodenal mucosa of children with untreated CD compared with treated $\mathrm{CD}$ and controls $(p<0.05)$. The mRNA expression of CD73 and MDR1 was increased in children with treated $\mathrm{CD}$ compared with untreated and controls ( $p<0.01$ and $p<0.05$, respectively).

Protein levels of HIF-1 $\alpha$ in the duodenal mucosa. Western blot analysis of duodenal biopsy specimens from children with untreated $\mathrm{CD}$, children with treated $\mathrm{CD}$ and controls using anti-HIF- $1 \alpha$ rabbit polyclonal antibodies revealed one

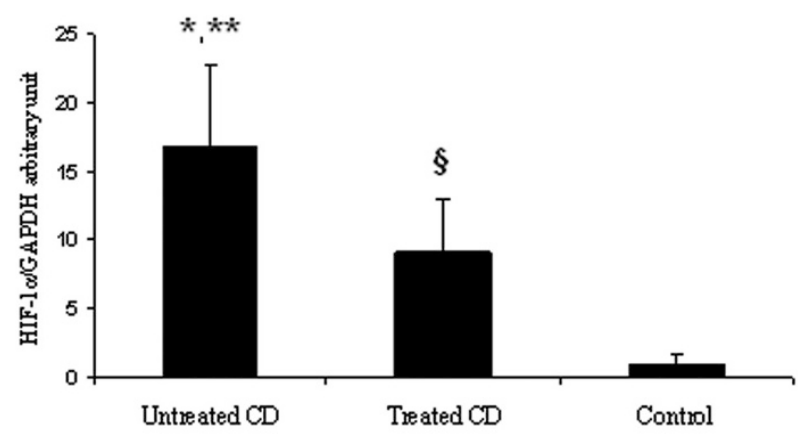

Figure 1. HIF- $1 \alpha$ expression in the duodenal mucosa of children with untreated $\mathrm{CD}$, children with treated $\mathrm{CD}$ and controls. Data for the mRNA expression of HIF- $1 \alpha$ were obtained by computerized analysis of PCR products. Optical density of the investigated RT-PCR products was corrected for that of GAPDH. Data are expressed as mean \pm SEM. Analysis of significance was performed by Mann-Whitney $\mathrm{U}$ test. ${ }^{*} p<0.01 v s$. treated $\mathrm{CD} ; * * p<0.01$ vs. control; $\$ p<0.01$ vs. control. 

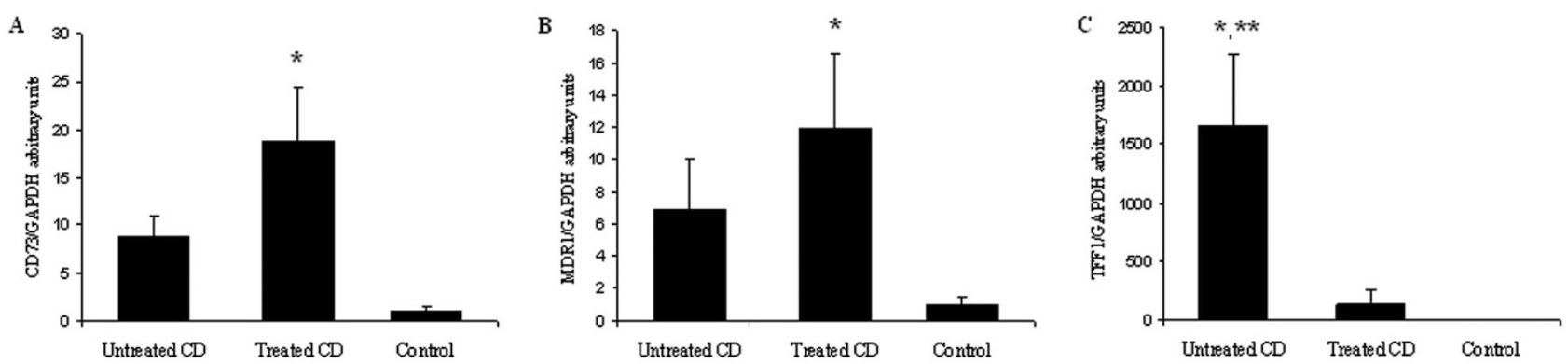

Figure 2. CD73, MDR1, and TFF1 mRNA expression in the duodenal mucosa of children with untreated CD, children with treated CD and controls. Data for the mRNA expression of HIF- $1 \alpha$ were obtained by computerized analysis of PCR products. Optical density of the investigated RT-PCR products was corrected for that of GAPDH. Data are expressed as mean \pm SEM. Analysis of significance was performed by Mann-Whitney $\mathrm{U}$ test. $* p<0.05 v s$. untreated CD and control, $* * * p<0.05$ vs. treated CD and control.
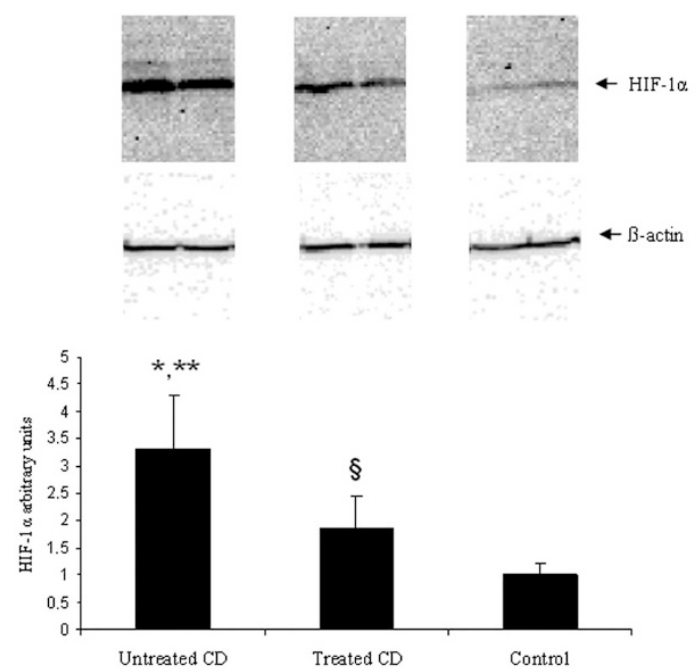

Figure 3. HIF-1 $\alpha$ protein levels in the duodenal mucosa from children with untreated CD, children with treated $\mathrm{CD}$ and controls. Western blot analysis of the duodenal biopsy lysates with anti-HIF-1 $\alpha$ rabbit polyclonal antibody reveals 1 distinct band at molecular weight of $130 \mathrm{kD}$. As housekeeping protein $\beta$-actin was measured. Data for protein levels of HIF-1 $\alpha$ were obtained by computerized analysis of the Western blots. Data are expressed as mean \pm SEM. Analysis of significance was performed by Mann-Whitney $\mathrm{U}$ test. $* p<0.01 v s$. treated $\mathrm{CD} ; * * p<0.01 v s$. control; $\$ p<0.01 v s$. control.

distinct band at about $130 \mathrm{kD}(\mathrm{HIF}-1 \alpha)$. HIF- $1 \alpha$ protein levels in the duodenal mucosa of children with untreated and treated $\mathrm{CD}$ were higher than in controls $(p<0.01)$. In the duodenal mucosa of children with treated $\mathrm{CD}$, HIF- $1 \alpha$ protein levels were, however, lower than in untreated $\mathrm{CD}(p<0.01)$ (Fig. 3).

Localization of HIF-1a in the duodenal mucosa. Figure $4 A-C$ show representative pictures about the cellular distribution of HIF- $1 \alpha$ in the duodenal villi of children with untreated (Fig. 4A) and treated CD (Fig. 4B) and controls (Fig. 4C). As shown in Fig. $4 A$ was the intense staining of HIF- $1 \alpha$ present in the whole width of villous enterocytes of the children with untreated $\mathrm{CD}$ in their basal membrane, intracellular space, and in their apical part of their cytoplasm as well. Translocation of HIF- $1 \alpha$ to the nucleus of the villous enterocytes indicates its activation. No fluorescent signal was detected in the goblet cells, in the cells of the Lieberkühn crypts, and in the immune cells of the lamina propria. In children with treated CD (Fig. $4 B$ ), the distribution of HIF- $1 \alpha$ was restricted to the basal membrane and it was not present in the nucleus of the enterocytes. In the biopsy specimen of the control children (Fig. $4 C$ ), HIF- $1 \alpha$ was barely detectable and only in the enterocytes.

\section{DISCUSSION}

Celiac disease (CD) is a chronic inflammatory disorder of the small intestine induced in genetically susceptible people by gluten and possibly other environmental factors $(18,19)$. Impairment of the intestinal barrier is a key event in $C D$, which leads to gluten entry across the epithelium and activation of the adaptive and innate immune system $(5,6,20,21)$.

The normal barrier function of the intestinal epithelium is tightly regulated to maintain the normal homeostasis (22). Recent data suggest the importance of the HIF-1 regulated genes in the maintenance of the intestinal epithelial barrier function (15). Although activation of HIF-1 is mainly regulated by hypoxia (23), it is now established that HIF-1 signaling can also be triggered under inflammatory conditions $(16,24,25)$. HIF-1 is a heterodimer transcriptional factor made up of an inducible HIF- $1 \alpha$ subunit and a constitutively expressed HIF-1 $\beta$ subunit (26). So far more than 70 target genes are known to be directly regulated by HIF-1 $(11,27)$. It has been shown that a number of these genes, such as TFF1, CD73, and MDR1, has intestinal epithelial barrier protective function (15).

In our study, we have investigated the alteration of the amount and localization of HIF- $1 \alpha$ in duodenal biopsy samples taken from children with untreated CD, as well as from children with treated CD and controls. Here, we have demonstrated elevated amount of HIF- $1 \alpha$ in the duodenal enterocytes of children suffering from $\mathrm{CD}$. Moreover, we observed the translocation of HIF- $1 \alpha$ into the nucleus of the villous enterocytes in untreated $\mathrm{CD}$ children, indicated its active role in the pathomechanism of CD (Fig. 4).

To the best of our knowledge, we suggest first the role of HIF- $1 \alpha$ in the pathomechanism of CD and only there are few previous data about HIF-1 in other inflammatory bowel disease (IBD) (28). In the absence of experimental model of CD, it is difficult to decide the exact role of increased HIF- $1 \alpha$ level in the pathomechanism of $\mathrm{CD}$. However, previous studies on IBD may give some suggestion. Karhausen et al.(15) investi- 

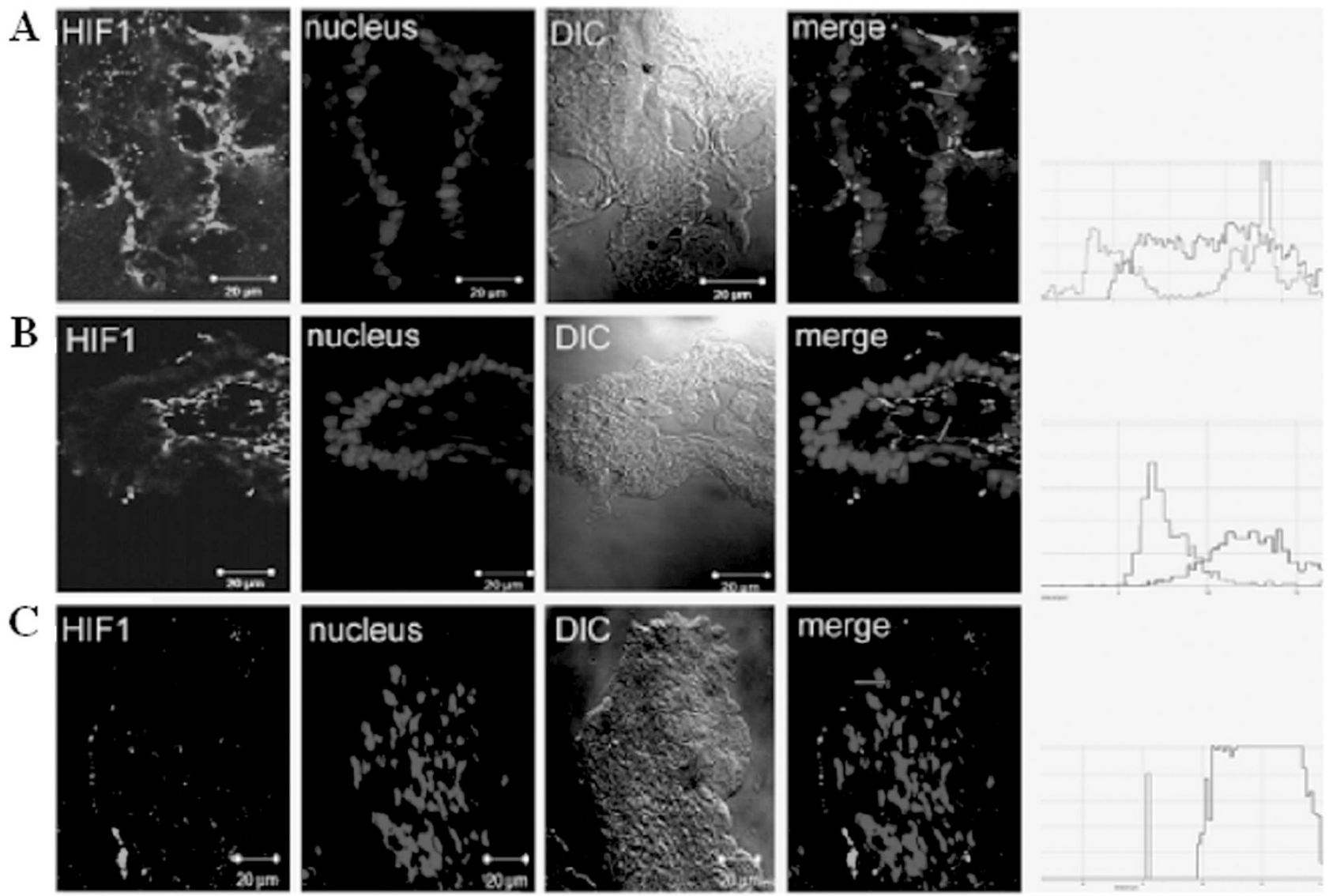

Figure 4. Localization of HIF-1 $\alpha$ in the duodenal mucosa of representative samples from children with untreated CD, children with treated CD and controls. Frozen duodenal villous sections were fixed and immunofluorescent staining was performed using anti-HIF-1 $\alpha$ (green) antibody. Nuclei are stained with blue. Intense staining of HIF-1 $\alpha$ was present in the basal membrane, intracellular space and apical part of the cytoplasm of the villous enterocytes of the children with untreated CD $(A)$. Translocation of HIF-1 $\alpha$ into the nucleus of the villous enterocytes indicates its activation. In children with treated CD $(B)$, the distribution of HIF-1 $\alpha$ was restricted to the basal membrane and it was not present in the nucleus of the enterocytes. In the biopsy specimen of the control children $(C)$, HIF- $1 \alpha$ was barely detectable and only in the enterocytes. DIC pictures show longitudinal (untreated CD and controls) or horizontal sections of duodenal villi (treated CD). Confocal images were taken on a Zeiss Axiovert LSM510 with the plan apochromat $63 \times / 1.40$ Oil DIC. Fluorescence signal intensities of HIF-1 $\alpha$ (green) and the nucleus (blue) generated from a scanned horizontal line shown as a red item in the merged image are shown on the right side of each panel.

gated the role of HIF-1 in a murine model of colitis. They have generated mouse lines with intestinal epithelial cell targeted expression of either mutant von Hippel Lindau gene (constitutively active HIF-1 $\alpha$ ) or mutant HIF- $1 \alpha$ (unability of the formation of active HIF-1 $\alpha$ ). In animals, which constitutively expressed active HIF- $1 \alpha$, did not develop a spontaneous IBD, indeed using 2,4,6-trinitrobenzene sulfonic acid (TNBS) it was difficult to provoke IBD. These data suggest that increased HIF- $1 \alpha$ level may rather be a consequence then a cause of CD.

Even though, the incompleteness of our knowledge, the previous studies on IBD almost uniformly suggest that increased level of HIF-1 may provide an overall protective effect both in in vitro (29) and in vivo experimental model of colitis $(15,30,31)$. Case reports propose that hyperbaric oxygen treatment of the patients has beneficial effects on the clinical symptoms of IBD $(32,33)$. In line with the human studies Karhausen et al.(15) demonstrated that in animals, which expressed mutant HIF-1 $\alpha$, the clinical symptoms of the TNBS-induced colitis were more severe then in animals, which constitutively expressed HIF-1 suggesting the protective role of increased HIF-1 signaling. More recently, in accordance with Karhausen et al., Shah et al.(30) suggested the possible protective role of increased HIF- $1 \alpha$ signaling during the early phase of IBD. They found that the increased activity of HIF-1 resulted in better preserved barrier function of the animals with experimental colitis.

However, the pathomechanism of $\mathrm{CD}$ differs from that of IBD (34), we hypothesized that the biologic function of activated HIF-1 signaling may be similar in the both case. So we have investigated the mRNA expression of TFF1, CD73, and MDR1. Previously, these HIF-1 regulated genes were demonstrated to have barrier protective role in IBD (15).

In accordance with findings in IBD (15) we have found increased mRNA expression of TFF1 in the duodenal biopsy specimen of untreated CD children compared with control samples. TFFs are the main secretory product of the injured intestinal epithelia $(35,36)$, which affect the integrity of the epithelia in many ways: TFFs enhance the rapid repair and the differentiation of the injured epithelium and stabilize the epithelial barrier (37).

Interestingly, the mRNA expression of CD73 and MDR1 were increased not in the duodenal biopsy specimen of the untreated however in that of treated CD children compared with controls. CD73 has been demonstrated to metabolize the AMP to adenosine, which by binding to $A_{2}$ receptors may 
protect integrity of the cellular barrier $(38,39)$ thus alter the epithelial and endothelial permeability. MDR-1 gene has similar function. In the intestine P-glycoprotein (P-gp), the product of the MDR-1 gene (40) constitutes a barrier, it transport the toxins into the intestinal lumen thereby preventing the integrity of the intestinal epithelial cells (41). These data suggest that while TFF1 may have a role in the acute regeneration of the epithelial barrier function, CD73 and MDR1 rather have a role in the chronic maintenance of the vulnerable epithelial barrier of the children with treated CD.

In summary, our results of increased mucosal HIF- $1 \alpha$ expression in untreated $\mathrm{CD}$ children suggest the contribution of this signaling pathway in the pathomechanism of $\mathrm{CD}$. In children with $\mathrm{CD}, \mathrm{HIF}-1 \alpha$ may participate in the maintenance of the barrier function of the intestinal epithelial cells partially through the altered expression of TFF1, MDR1, and CD73. Moreover, decreased mucosal expression HIF- $1 \alpha$ in treated CD may confirm the efficiency of the gluten free diet, besides the normal histologic findings.

Acknowledgments. We thank Maria Bernáth for her excellent technical assistance.

\section{REFERENCES}

1. Johnston SD, Watson RG, McMillan SA, Sloan J, Love AH 1997 Prevalence of coeliac disease in Northern Ireland. Lancet 350:1370

2. Sanders DS, Patel D, Stephenson TJ, Ward AM, McCloskey EV, Hadjivassiliou M, Lobo AJ 2003 A primary care cross-sectional study of undiagnosed adult coeliac disease. Eur J Gastroenterol Hepatol 15:407-413

3. West J, Logan RF, Hill PG, Lloyd A, Lewis S, Hubbard R, Reader R, Holmes GK, Khaw KT 2003 Seroprevalence, correlates, and characteristics of undetected coeliac disease in England. Gut 52:960-965

4. Fasano A, Berti I, Geraduzzi T, Not T, Colletti RB, Drago S, Elitsur Y, Green PH, Guandalini S, Hill ID, Pietzak M, Ventura A, Thorpe M, Kryszak D, Fornaroli F, Wasserman SS, Murray JA, Horvath K 2003 Prevalence of coeliac disease in at-risk and not-at-risk groups in the United States. Arch Intern Med 163:286-292

5. Stepniak D, Koning F 2006 Celiac disease-sandwiched between innate and adaptive immunity. Hum Immunol 67:460-468

6. Koning F 2005 Celiac disease: caught between a rock and a hard place. Gastroenterology 129:1294-1301

7. Furuta GT, Turner JR, Taylor CT, Hershberg RM, Comerford K, Narravula S, Podolsky DK, Colgan SP 2001 Hypoxia-inducible factor 1-dependent induction of intestinal trefoil factor protects barrier function during hypoxia. J Exp Med 193:1027-1034

8. Synnestvedt K, Furuta GT, Comerford KM, Louis N, Karhausen J, Eltzschig HK, Hansen KR, Thompson LF, Colgan SP 2002 Ecto-5'-nucleotidase (CD73) regulation by hypoxia-inducible factor-1 mediates permeability changes in intestinal epithelia. J Clin Invest 110:993-1002

9. Adams JM, Difazio LT, Rolandelli RH, Luján JJ, Haskó G, Csóka B, Selmeczy Z, Németh ZH 2009 HIF-1: a key mediator in hypoxia. Acta Physiol Hung 96:19-28

10. Salceda S, Caro J 1997 Hypoxia-inducible factor 1alpha (HIF-1alpha) protein is rapidly degraded by the ubiquitin-proteasome system under normoxic conditions. Its stabilization by hypoxia depends on redox-induced changes. J Biol Chem 272:22642-22647

11. Wenger RH, Stiehl DP, Camenisch G 2005 Integration of oxygen signaling at the consensus HRE. Sci STKE 2005:re12

12. Hoffmann W 2005 Trefoil factors TFF (trefoil factor family) peptide-triggered signals promoting mucosal restitution. Cell Mol Life Sci 62:2932-2938
13. Colgan SP, Eltzschig HK, Eckle T, Thompson LF 2006 Physiological roles for ecto-5'-nucleotidase (CD73). Purinergic Signal 2:351-360

14. Annese V, Valvano MR, Palmieri O, Latiano A, Bossa F, Andriulli A 2006 Multidrug resistance 1 gene in inflammatory bowel disease: a meta-analysis. World J Gastroenterol 12:3636-3644

15. Karhausen J, Furuta GT, Tomaszewski JE, Johnson RS, Colgan SP, Haase VH 2004 Epithelial hypoxia-inducible factor-1 is protective in murine experimental colitis. J Clin Invest 114:1098-1106

16. Hirota SA, Beck PL, MacDonald JA 2009 Targeting hypoxia-inducible factor-1 (HIF-1) signaling in therapeutics: implications for the treatment of inflammatory bowel disease. Recent Pat Inflamm Allergy Drug Discov 3:1-16

17. Walker-Smith JA, Guandalini S, Schmitz J, Shmerling DH, Visakorpi JK 1990 Revised criteria for diagnosis of coeliac disease. Report of Working Group of European Society of Paediatric Gastroenterology and Nutrition. Arch Dis Child 65:909-911

18. Setty M, Hormaza L, Guandalini S 2008 Celiac disease: risk assessment, diagnosis, and monitoring. Mol Diagn Ther 12:289-298

19. Leeds JS, Hopper AD, Sanders DS 2008 Coeliac disease. Br Med Bull 88:157-170

20. Koning F, Gilissen L, Wijmenga C 2005 Gluten: a two-edged sword. Immunopathogenesis of celiac disease. Springer Semin Immunopathol 27:217-232

21. Szebeni B, Veres G, Dezsofi A, Rusai K, Vannay A, Bokodi G, Vásárhelyi B, Korponay-Szabó IR, Tulassay T, Arató A 2007 Increased mucosal expression of Toll-like receptor (TLR)2 and TLR4 in coeliac disease. J Pediatr Gastroenterol Nutr 45:187-193

22. Groschwitz KR, Hogan SP 2009 Intestinal barrier function: molecular regulation and disease pathogenesis. J Allergy Clin Immunol 124:3-20

23. Weidemann A, Johnson RS 2008 Biology of HIF-1alpha. Cell Death Differ 15:621-627

24. Yee Koh M, Spivak-Kroizman TR, Powis G 2008 HIF-1 regulation: not so easy come, easy go. Trends Biochem Sci 33:526-534

25. Dehne N, Brüne B 2009 HIF-1 in the inflammatory microenvironment. Exp Cell Res 315:1791-1797

26. Wang GL, Jiang BH, Rue EA, Semenza GL 1995 Hypoxia-inducible factor 1 is a basic-helix-loop-helix-PAS heterodimer regulated by cellular $\mathrm{O}_{2}$ tension. Proc Nat Acad Sci U S A 92:5510-5514

27. Ziello JE, Jovin IS, Huang Y 2007 Hypoxia-Inducible Factor (HIF)-1 regulatory pathway and its potential for therapeutic intervention in malignancy and ischemia. Yale J Biol Med 80:51-60

28. Taylor CT, Colgan SP 2007 Hypoxia and gastrointestinal disease. J Mol Med 85:1295-1300

29. Cummins EP, Seeballuck F, Keely SJ, Mangan NE, Callanan JJ, Fallon PG, Taylor CT 2008 The hydroxylase inhibitor dimethyloxalylglycine is protective in a murine model of colitis. Gastroenterology 134:156-165

30. Shah YM, Ito S, Morimura K, Chen C, Yim SH, Haase VH, Gonzalez FJ 2008 Hypoxia inducible factor augments experimental colitis through an MIF-dependent inflammatory signaling cascade. Gastroenterology 134:2036-2048, 2048.e12048.e3

31. Robinson A, Keely S, Karhausen J, Gerich ME, Furuta GT, Colgan SP 2008 Mucosal protection by hypoxia-inducible factor prolyl hydroxylase inhibition. Gastroenterology 134:145-155

32. Noyer CM, Brandt LJ 1999 Hyperbaric oxygen therapy for perineal Crohn's disease Am J Gastroenterol 94:318-321

33. Buchman AL, Fife C, Torres C, Smith L, Aristizibal J 2001 Hyperbaric oxygen therapy for severe ulcerative colitis. J Clin Gastroenterol 33:337-339

34. Agarwal S, Mayer L 2010 Gastrointestinal manifestations in primary immune disorders. Inflamm Bowel Dis 16:703-711

35. Wong WM, Playford RJ, Wright NA 2000 Peptide gene expression in gastrointestinal mucosal ulceration: ordered sequence or redundancy? Gut 46:286-292

36. Tarnawski A, Szabo IL, Husain SS, Soreghan B 2001 Regeneration of gastric mucosa during ulcer healing is triggered by growth factors and signal transduction pathways. J Physiol (Paris) 95:337-344

37. Hoffmann W 2004 Trefoil factor family (TFF) peptides: regulators of mucosa regeneration and repair, and more. Peptides 25:727-730

38. Linden J 2001 Molecular approach to adenosine receptors: receptor-mediated mechanisms of tissue protection. Annu Rev Pharmacol Toxicol 41:775-787

39. Weissmuller T, Eltzschig HK, Colgan SP 2005 Dynamic purine signaling and metabolism during neutrophil-endothelial interactions. Purinergic Signal 1:229-239

40. Schinkel AH 1997 The physiological function of drug-transporting P-glycoproteins. Semin Cancer Biol 8:161-170

41. Marzolini C, Paus E, Buclin T, Kim RB 2004 Polymorphisms in human MDR1 (P-glycoprotein): recent advances and clinical relevance. Clin Pharmacol Ther 75:13-33 